\title{
Incomplete or Inadequate Priming
}

National Cancer Institute

\section{Source}

National Cancer Institute. Incomplete or Inadequate Priming. NCI Thesaurus. Code

C133630.

Problem associated with not adequately preparing the device. 